\title{
THE CORRELATION OF TUMOR BUDDING INDEX WITH GRADING OF INFILTRATING UROTHELIAL CARCINOMA
}

\author{
Rahayu Asih Putri*, Lidya Imelda Laksmi*, Delyuzar*
}

Department of Anatomical Pathology, Faculty of Medicine, Universitas Sumatera Utara, Medan, Indonesia. *Corresponding Author

\begin{abstract}
Background: Urothelial carcinoma is the most common type of bladder cancer. WHO Classification of Tumors of Urinary System and Male Genital Organs 2016 classifies urothelial carcinoma based on its histological structure and cell morphology, namely, low grade urothelial carcinoma (LGUC) and high grade urothelial carcinoma (HGUC). Tumor grading should be reported because it is one of the important prognostic factors in infiltrating urothelial carcinoma. Tumor budding has been extensively studied and has been established as a prognostic factor in several types of carcinoma where it has independent predictive and prognostic relevance. Research on tumor budding is still very rarely done on infiltrating urothelial carcinoma and in Indonesia there are no published journals related to tumor budding on infiltrating urothelial carcinoma.

Research Objectives: To determine the correlation between tumor budding index and grading of infiltrating urothelial carcinoma
\end{abstract}

Materials and Methods: This study was an analytic study with a cross sectional approach on 38 samples of paraffin block patients diagnosed histopathologically as infiltrating urothelial carcinoma. Then, the paraffin blocks were re-cut and the slides stained with H\&E. The tumor budding index was assessed as < 10 buds (low grade) and 10 buds (high grade). The grading of infiltrating urothelial carcinoma is divided into two, namely low grade and high grade and is assessed based on cell morphology. The relationship between tumor budding index and grading of infiltrating urothelial carcinoma was statistically tested.

Results: The most age was 56-65 years, with a mean age of 62 years. Male gender was found more than female. The highest grading is high grade $(92.11 \%)$. There were 7 histopathological subtypes from 13 histopathological subtypes, the majority of the samples were infiltrating urothelial carcinoma with squamous differentiation subtype. LVI was found in 33 cases $(86.84 \%)$, and PNI was found in 8 cases $(21.05 \%)$. The most common budding tumors were high grade buds at $92.10 \%$.

Conclusion: The study showed a significant relationship between the tumor budding index and grading $(p$-value $=0.0001$ ) where the tumor budding index could be used to determine an independent prognosis that could predict disease progression.

Keywords: tumor budding, grading, infiltrating urothelial carcinoma

\section{INTRODUCTION}

B ladder cancer is a malignant tumor originating from transitional epithelial cells that line the mucosal lining of the bladder. ${ }^{1}$ According to Globocan data in 2018, bladder cancer in general is the 11th most common cancer in the world, with an estimated 549,000 new cases (3.0\%) and 200,000 deaths (2.1\%). ${ }^{2}$ While in Indonesia bladder cancer ranks fourteenth with about 6,716 new cases $(1.9 \%)$ and 3,375 deaths $(1.6 \%)$, and has a 5year prevalence rate for all age $17,151(6.43 \%) .{ }^{3}$ The incidence of bladder cancer is higher in men than in women, with approximately three-quarters of all bladder cancer cases diagnosed in men. ${ }^{4}$

Bladder cancer is 3-4 times more common in men than women. The mean age of the patients at diagnosis was $65-70$ years. The prevalence of bladder cancer in men compared with women is not fully explained by differences in known risk factors such as smoking and occupational exposure. Mortality rates also differ between sexes, with 2-10 deaths per 100,000 males per year, and 0.5-4 deaths per 100,000 females per year. ${ }^{4}$

Based on the 2016 World Health Organization (WHO) classification, urothelial tumors are divided into two major groups, namely infiltrating urothelial carcinoma and noninvasive urothelial lesions. Infiltrating urothelial carcinoma is a carcinoma originating from urothelial epithelial cells that line the urinary tract that invades through the basement membrane into the underlying tissue and has different differentiation tendencies. ${ }^{4,5}$

WHO classifies urothelial carcinoma based on its histological structure and cell morphology, namely, low grade urothelial carcinoma (LGUC) and high grade urothelial carcinoma (HGUC). Tumor grading should be reported because histopathological grading is an important prognostic factor in infiltrating urothelial carcinoma. ${ }^{5,6,7}$

Tumor budding is the presence of isolated tumor cells or small clusters of up to four tumor cells ("buds"), located in the stroma in front of the invasive tumor cells. The phenomenon of tumor budding can be observed peritumorally and intratumorally. ${ }^{8}$ Many authors consider this phenomenon to be a morphological representation of the acquisition of invasive capabilities by tumor cells and is considered to be the initiation of metastasis. This cell phenotype is characteristic that leads to migration (loss of epithelial markers such as E-cadherin and increase of mesenchymal markers such as vimentin or fibronectin). Therefore, tumor budding is associated with the epithelial-mesenchymal transition (EMT). ${ }^{9,10}$

Tumor budding has been extensively studied and established as an important prognostic factor. In addition to the several prognostic factors that have been established for infiltrating urothelial carcinoma of the bladder, it is important to identify 
additional prognostic markers that will enable us to further categorize patients into risk groups and thereby develop personalized and more effective follow-up and adjuvant therapies. ${ }^{11}$ Tumor budding research is still very rarely done on infiltrating urothelial carcinoma of the bladder and in Indonesia alone there are no published journals related to tumor budding in urothelial carcinoma. This makes researchers interested in conducting a study to assess tumor budding in infiltrating urothelial carcinoma with the aim of being able to be used as an additional independent prognostic factor for making surgical decisions, as a screening of patients who need adjuvant therapy and decisions to make the management process for urothelial carcinoma.

\section{MATERIAL AND METHODS}

This analytical study with a cross-sectional approach was conducted at the Laboratory of Anatomic Pathology, Faculty of Medicine, University of North Sumatra, Medan. This research was conducted from December 2020 to July 2021, after obtaining approval from the Health Research Ethics Committee, Faculty of Medicine, University of North Sumatra.

The sample of this study was a paraffin block from patients who had been diagnosed histopathologically as infiltrating urothelial carcinoma that met the inclusion and exclusion criteria. Samples were taken using consecutive sampling technique. Inclusion criteria included adequate clinical data in the medical record (indicating age and gender) as well as representative paraffin slides or blocks, derived from tissue results after trans urethral resection of bladder tumor (TURBT) diagnosed histopathologically as infiltrating urothelial carcinoma with staining. H\&E. The exclusion criteria for this study were unrepresentative paraffin slides or blocks so they could not be reprocessed. Each sample was re-cut and stained with H\&E.

Intratumoral tumor budding is the growth of tumor cell buds between tumor nests on histopathological preparations with H\&E staining. The assessment of tumor budding refers to a study conducted by Fukumoto, in which the number of tumor buds was categorized as follows, if $<10$ buds (low grade buds) and 10 buds (high grade buds).12 The grading system refers to the WHO classification for the tumor system. urinary tract and male genital organs in 2016 and assessed based on cell morphology.5 The relationship between tumor budding index and grading of infiltrating urothelial carcinoma was statistically tested.

\section{RESULT}

In this study, 38 samples of infiltrating urothelial carcinoma were obtained at the Laboratory of Anatomic Pathology, Faculty of Medicine, University of North Sumatra, Medan. The highest age was 56-65 years, with an average age of 62 years. There are more males than females. There are 7 histopathological subtypes from 13 histopathological subtypes with the majority of samples being infiltrating urothelial carcinoma with squamous differentiation subtypes. LVI was found in 33 cases $(86.84 \%)$, and PNI was found in 8 cases $(21.05 \%)$. The most common budding tumors were high grade buds at $92.10 \%$ (Table 1 ).
Table 1. Characteristics of the study sample based on age, sex, grading, histopathological subtypes, lymphovascular invasion and perineural invasion in patients with infiltrating urothelial carcinoma

\begin{tabular}{|c|c|c|}
\hline Characteristics & $(\mathrm{n}=38)$ & $\begin{array}{c}\text { Persentase } \\
(\%)\end{array}$ \\
\hline \multicolumn{3}{|l|}{ Age (years old): } \\
\hline $26-35$ & 2 & 5,26 \\
\hline $36-45$ & 7 & 18,42 \\
\hline $46-55$ & 3 & 7,90 \\
\hline $56-65$ & 14 & 36,84 \\
\hline $66-75$ & 7 & 18,42 \\
\hline $76-85$ & 5 & 13,16 \\
\hline \multicolumn{3}{|l|}{ Sex } \\
\hline Male & 25 & 65,79 \\
\hline Female & 13 & 34,21 \\
\hline \multicolumn{3}{|l|}{ Grading } \\
\hline Low grade & 3 & 7,89 \\
\hline High grade & 35 & 92,11 \\
\hline \multicolumn{3}{|l|}{ Histopathology subtype } \\
\hline $\begin{array}{l}\text { Infiltrating urothelial carcinoma with squamous } \\
\text { differentiation }\end{array}$ & 17 & 44,73 \\
\hline $\begin{array}{l}\text { Infiltrating urothelial carcinoma with glandular } \\
\text { differentiation }\end{array}$ & 2 & 5,26 \\
\hline $\begin{array}{l}\text { Infiltrating urothelial carcinoma with } \\
\text { trophoblastic differentiation }\end{array}$ & 0 & \\
\hline Nested urothelial carcinoma & 3 & 7,89 \\
\hline Microcystic urothelial carcinoma & 1 & 2,64 \\
\hline Micropapillary urothelial carcinoma & 0 & \\
\hline Plasmacytoid urothelial carcinoma & 0 & \\
\hline Sarcomatoid urothelial carcinoma & 0 & \\
\hline Lymphoepithelioma-like urothelial carcinoma & 1 & 2,64 \\
\hline Giant cell urothelial carcinoma & 0 & \\
\hline $\begin{array}{l}\text { Poorly differentiated tumor (termasuk } \\
\text { osteoclast-like giant cell) }\end{array}$ & 2 & 5,26 \\
\hline Sarcomatoid rich urothelial carcinoma & 0 & \\
\hline \multirow{2}{*}{\multicolumn{3}{|c|}{ Lymphovascular invasion }} \\
\hline & & \\
\hline No & 5 & 13,16 \\
\hline & 33 & 86,84 \\
\hline \multicolumn{3}{|l|}{ Perineural invasion } \\
\hline No & 30 & 78,95 \\
\hline Present & 8 & 21,05 \\
\hline
\end{tabular}

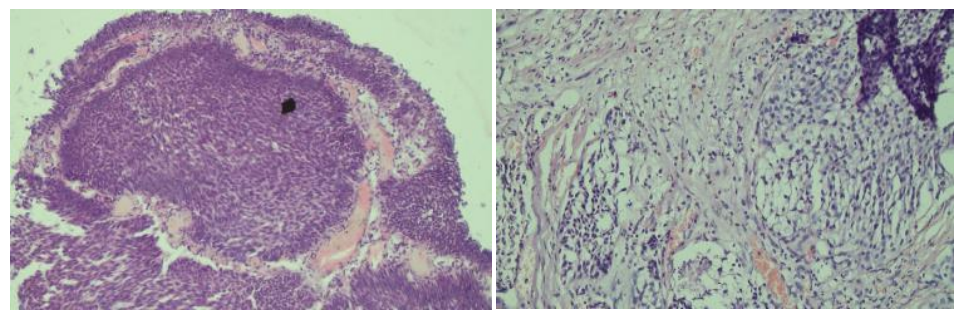

Figure 1. Low grade buds $(H \& E, 200 \mathrm{X})$. B. High grade buds $(H \& E, 200 \mathrm{X})$.

In this study, the relationship between tumor budding index and grading of infiltrating urothelial carcinoma was assessed. The most common budding tumors were high-grade budding with 35 samples $(92.10 \%)$. The study showed a significant relationship between the tumor budding index and grading ( $\mathrm{p}$ value $=0.0001)($ Table 2$)$

Table 2. Relationship between tumor budding index and grading of infiltrating urothelial carcinoma.

\begin{tabular}{cccccc}
\hline \multirow{2}{*}{$\begin{array}{c}\text { Tumor Budding } \\
\text { Index }\end{array}$} & \multicolumn{6}{c}{ Low grade } & High grade & \multirow{2}{*}{ P-value* $^{*}$} \\
\hline Low grade buds & 3 & 100 & 0 & 0 & \\
High grade buds & 0 & 0 & 35 & 100 & 0,0001 \\
Total & 3 & 7,9 & 35 & 92,1 & \\
\hline * & N & & &
\end{tabular}

* Fisher's Exact test 


\section{DISCUSSION}

The number of samples diagnosed as infiltrating urothelial carcinoma in this study were 38 samples, where the most patients were aged 56-65 years, with a mean of 62 years, the youngest age was 27 years and the oldest was 82 years. The results of this study are not much different from previous studies. Suren et al. in 2018 found that the mean age of the patients was 70 years with a standard deviation of 12.07 years and the age range in the study was 26-94 years.13 Ahmed et al. in 2018 also stated that urothelial carcinoma occurs at an average age of 50 years. ${ }^{14}$ The diagnosis of urothelial carcinoma is often difficult to establish because it almost has the same symptoms as other diseases such as urinary tract infections and urinary stones. This delay in diagnosis is the cause of the increased morbidity of urothelial carcinoma and a definite diagnosis is most often found at a relatively older age. ${ }^{1}$

The discovery of young patients proves that at this time, younger patients with infiltrating urothelial carcinoma have been reported. Patients with infiltrating urothelial carcinoma at a young age can be caused by several risk factors that can trigger the occurrence of urothelial carcinoma, including genetic factors and smoking habits. Where with a family history of suffering from urothelial carcinoma increases the risk of urothelial carcinoma in their offspring. Likewise with the younger age of people who smoke where the chemicals in cigarettes contribute greatly to the risk of urothelial carcinoma.

The number of samples of infiltrating urothelial carcinoma based on gender, male sex was found to be more than 25 samples $(65.79 \%)$ and female sex was 13 samples $(34.21 \%)$, with a male to female ratio of $2: 1$. These results are in line with the research conducted by Ahmed et al. in 2018 which showed that urothelial carcinoma was more common in men, which was $70 \% .{ }^{14}$ Research by Hashmi et al. in 2018 also obtained the same results that the male gender was more than the female sex, namely $72.2 \% .{ }^{15}$ But the results of research conducted by Zhang et al. in 2018 , reported a difference in the ratio between the sexes of men compared to women with a ratio of $4.6: 1 .{ }^{16}$ The difference in the ratio in this study can be attributed possibly to differences in the study population. The incidence and severity of disease varies between sexes and may be related to differences in exposure to carcinogens, environmental factors and physiological and cellular responses. Urothelial carcinoma affects more men than women, but the prognosis of men with urothelial carcinoma is better than that of women. In fact, although urothelial carcinoma is 3-4 times more common in men than in women, the mortality rate from urothelial carcinoma is lower in men than in women. Excessive exposure to carcinogens such as tobacco and industrial chemicals in men has been reported as a risk factor for urothelial carcinoma in men. Several alternative hypotheses have been reported, including genetic, anatomical, hormonal, social and environmental factors, to explain the behavior of urothelial carcinoma differentiation between genders related to steroid hormones and their receptors. ${ }^{17}$

Based on the classification of urothelial tract tumors according to WHO in 2016, infiltrating urothelial carcinoma consists of ten histopathological subtypes, with three differentiations. ${ }^{5}$ In this study, researchers assessed the histopathological subtypes based on histomorphological features with $\mathrm{H} \& \mathrm{E}$ staining. The researchers only found seven histopathology subtypes of all histopathological subtypes in infiltrating urothelial carcinoma, the majority of which were infiltrating urothelial carcinoma with squamous differentiation subtype, namely 17 samples (44.73\%), and 12 clear cell (glycogen rich) urothelial carcinoma, respectively. 3 samples $(31.58 \%)$ nested urothelial carcinoma (7.89\%), poorly differentiated urothelial carcinoma 2 samples (5.26\%), infiltrating urothelial carcinoma with glandular differentiation 2 samples $(5.26 \%)$, the remaining 1 sample of microcystic urothelial carcinoma $(2,64 \%)$ and 1 sample of lymphoepithelioma-like urothelial carcinoma $(2,64 \%)$. In line with the research conducted by Santana et al. in 2020 reported that the most commonly found subtype was infiltrating urothelial carcinoma with squamous differentiation as much as $39 \% .{ }^{18}$ According to Shah et al. in 2012 reported that 32\% were histopathological subtypes of squamous differentiation. ${ }^{19}$ According to Kassouf et al. in 2009 reported that subtype determination of infiltrating urothelial carcinoma can be a significant independent predictor of overall survival and recurrence-free survival in urothelial carcinoma patients who have undergone neoadjuvant chemotherapy. ${ }^{20}$ Each histopathological subtype is characterized by different morphological features. In addition, patients with certain histopathological subtypes may benefit from and respond differently to therapeutic interventions.

The National Comprehensive Cancer Network (NCCN) states the importance of accurate recognition and classification of histopathological subtypes of urothelial carcinoma because it is potentially aggressive and can be used as a guide for patients with non-urothelial carcinomas including urothelial carcinomas that show mixed histology and neuroendocrine components. Therefore, it is very important for pathologists to be able to reliably recognize histopathology for appropriate management of urothelial carcinoma patients. ${ }^{19,20}$ Knowledge to report histopathological subtypes of infiltrating urothelial carcinoma is needed because it is very useful for clinicians in terms of management and patient prognosis. optimal for urothelial carcinoma. The differences in the results in this study could be attributed to the possibility that inter-observer variability among pathologists may have contributed to the reported differences.

In this study, there were as many as $92.11 \%$ of the samples of infiltrating urothelial carcinoma were high-grade where the most common was found in the histopathological subtype of infiltrating urothelial carcinoma with squamous differentiation as many as 17 samples, the remaining 3 samples $(7.89 \%)$ were low grade where found in the histopathological subtype of nested urothelial carcinoma. According to research conducted by Choi, et al. in 2012 reported that $64.6 \%$ of urothelial carcinomas were high grade.21 Research conducted by Messer et al. in 2011 reported that $67 \%$ of urothelial carcinoma was high grade..$^{22}$ The results of this study are not much different from the study conducted by Li et al. in 2017 found that high grade cases were $58 \%$ of urothelial carcinoma. ${ }^{23}$ The infiltrative growth pattern of infiltrating urothelial carcinoma may be associated with a poorer prognosis. Where according to research conducted by Jimenez et al. in 2000 stated that the presence of an infiltrative pattern in tumors was associated with a median survival of 29 months, compared with 85 months in tumors without an infiltrative pattern $(\mathrm{p}=0.06){ }^{24}$ The nested variant in infiltrating urothelial 
carcinoma is a rare variant, generally is a low grade indicated by an enlarged nucleus which often indicates a benign process. ${ }^{25}$

In this study, lymphovascular invasion was found in $86.84 \%$. The remaining 5 samples did not find lymphovascular invasion $(13.16 \%)$. In a study conducted by Soriano et al. in 2019 found $57.54 \%$ lymphovascular invasion. ${ }^{10}$ Yoo et al. in 2020 reported the presence of lymphovascular invasion as much as $69 \%$ of all samples studied. ${ }^{26}$ However, in the study conducted by Fukumoto et al. reported that only $24.8 \%$ found the presence of lymphovascular invasion of all samples studied. ${ }^{12}$ Lymphovascular invasion was defined as the presence of tumor cells in the lumen of arteries, veins, or lymphatics. Lymphovascular invasion has been reported to be independently associated with recurrence and progression of cancer cells. ${ }^{27}$ Its presence is also considered a strong prognostic marker of tumor aggressiveness and an indicator of hidden metastasis in several malignancies, including urothelial carcinoma. ${ }^{28}$ Tilki et al. reported that lymphatic invasion was associated with nodal metastasis and poorer cancer-specific survival. ${ }^{29}$

In this study, the perineural invasion was reported in 8 samples $(21.05 \%)$. The remaining 30 samples $(78.95 \%)$ did not find perineural invasion. A study conducted by Soriano et al. in 2019 reported the presence of perineural invasion as much as $19.81 \%$ of all samples studied. ${ }^{10}$ However, Yoo et al. in 2020 found $46 \%$ perineural invasion. ${ }^{26}$ The prognostic significance of perineural invasion in urothelial carcinoma is still unknown. The research of Muppa et al. in 2017 using tissue resulting from cystectomy reported that the presence of perineural invasion is rare. Patients with perineural invasion had a worse outcome than patients without perineural invasion. In addition, the perineural invasion was not associated with increased local recurrence. ${ }^{30}$ Perineural invasion showed tumor cells very close to the nerve and its surroundings, at least $33 \%$ of the nerve margin or tumor cells invading the three layers of the neurolemma structure. Perineural invasion can be found in a variety of malignant tumors. Perineural invasion is a sign of tumor metastasis and indicates a poor patient prognosis. ${ }^{31}$ There is considerable variability in the reported incidence of perineural invasion in urothelial carcinoma, possibly due to differences in study sampling. In this study, samples were taken from the TURBT results.

In this study, the most budding tumors were high grade buds as much as $92.10 \%$ compared to low grade buds only $7.90 \%$. From the analysis of the relationship between tumor budding index and grading, it was found that the $p$-value $=0.0001$, it can be concluded that there is a relationship between tumor budding index and grading in infiltrating urothelial carcinoma, where the tumor budding index with high grade buds is most often found in cases of infiltrating urothelial carcinoma. with high grade carcinoma, it can be concluded that there is a significant relationship between an increase in the tumor budding index and an increase in grading. The results of this study are supported by Fukumoto et al. in 2016 which stated that there was a significant relationship between tumor budding and non-muscle invasive bladder cancer. ${ }^{12}$ Jesinghaus et al. in 2017 reported that there was a significant relationship between tumor budding and grading of esophageal squamous cell carcinoma with $\mathrm{p}$-value $<0.001 .^{32}$ According to Soriano et al. in 2019 reported that there was no significant relationship between tumor budding and grading of muscle-invasive bladder cancer with $\mathrm{p}$-value $=0.627$. Tumor budding has been reported as a prognostic marker in several different tumor types, predicting disease progression and poor survival. ${ }^{33}$ The difference in this study may lie in the study sample where in this study the relationship between tumor budding and grading of infiltrating urothelial carcinoma was assessed. while in the research conducted by Soriano et al. In 2019, an assessment of tumor budding was carried out with grading on muscle-invasive bladder cancer.

\section{CONCLUSION}

After conducted this study, we conclude some points in the following:

1. Patients with infiltrating urothelial carcinoma mostly occur at the age of 56-65 years with a mean age of 62 years, where the youngest age is 27 years and the oldest age is 82 years. Most gender is male. Most grading is high grade. The highest tumor budding index was high grade buds. There is a significant relationship between the tumor budding index and the grading of infiltrating urothelial carcinoma.

2. The most histopathological subtypes were infiltrating urothelial carcinoma with squamous differentiation, followed by clear cell urothelial carcinoma, then nested urothelial carcinoma, then infiltrating urothelial carcinoma with glandular differentiation and poorly differentiated urothelial carcinoma, the rest were microcystic urothelial carcinoma and lymphoepithelioma-like urothelial carcinoma.

3. The presence of lymphovascular invasion was found as much as $86.84 \%$.

4. Perineural invasion was $21,05 \%$.

\section{REFERENCES}

[1] Syafa'ah AN, Maulani H, Suciati T. Angka Kejadian Urothelial carcinoma di Bagian Patologi Anatomi RSUP dr. Mohammad Hoesin Palembang Periode Tahun 2009-2013. 2015:10-16.

[2] International Agency for Research on Cancer. Asia, Source : Globocan $2018 . \quad$ Available from: http://gco.iarc.fr/today/data/factsheets/populations/900-world-fact sheets.pdf.

[3] International Agency for Research on Cancer. Asia, Source: Globocan $2018 . \quad$ Available from: http://gco.iarc.fr/today/data/factsheets/populations/360-indonesia factsheets.pdf

[4] Humphrey PA, Moch H, Cubilla AL, Ulbright TM, Reuter VE. The 2016 WHO Classification of Tumours of the Urinary System and Male Genital Organs-Part B: Prostate and Bladder Tumours. Eur Urol. 2016;70(1):10619.

[5] Grignon DJ, Al-Ahmadie H, Algaba F, Amin MB, Comperat E, Dyrskjot $\mathrm{L}$, et al. Urothelial tumours infiltrating urothelial carcinoma. In: Moch $\mathrm{H}$, Humphrey PA, Ulbright TM, Reuter VE, editors. WHO Classification of tumours of the urinary system and male genital organs. 4th Ed. Lyon: IARC; 2016. P.77-98. 
[6] Eble JN, Guido S, Jonathan I.E, Isabell AS. WHO Pathology and Genetics of Tumours of the Urinary System and Male Genital Organs. France: IARC Press; 2004. P.90-91, 93-94, 98-99, 101-103.

[7] Cheng L, Lopez-Beltran A, MacLennan GT, Montironi R, Bostwick DG. Neoplasms of the urinary bladder. In Bostwick DG, Cheng L, editors. Urologic Surgical Pathology, Third Ed. Philadelphia: Elsevier Saunders; 2014. P.230-278.

[8] Lugli A, Kirsch R, Ajioka Y, Bosman F, Cathomas G, Dawson H, et al. Recommendations for Reporting Tumor Budding in Colorectal Cancer based on the International Tumor Budding Consensus Conference (ITBCC) 2016. Mod Pathol. 2017;30:1299-1311.

[9] Ammour KE, Bader M, Ahrens TD, Franke K, Timme S, Csanadi A, et al. From Follows Function: Morphological and Immunohistological Insights into Epithelial-Mesenchymal Transition Characteristics Of Tumor Buds. Tumour Biology. 2017;39(5):1-11. doi: 1010428317705501.

[10] Soriano LL, Jurado GO, Moreno JL, Castillo SV, Giron SH, Moreno IS, et al. Tumor Budding: Prognostic Value in Muscle-invasive Bladder Cancer. Urology. 2019;130: 93-98.

[11] Choi W, Porten S, Kim S, Willis D, Plimack ER, Censits JH, et al. Identification of Distinct Basal and Luminal Subtypes of Muscle-Invasive Bladder Cancer with Different Sensitivities to Frontline Chemotherapy. Cancer Cell. 2014;25:152-165. Available from: doi: 10.1016/j.ccr.2014.01.009.

[12] Fukumoto K, Kikuchi E, Mikami S, Ogihara K, Matsumoto K, Miyajima A, et al. Tumor Budding, a Novel Prognostic Indicator for Predicting Stage Progression in T1 Bladder Cancers. Japanese Cancer Association. 2016;107: 1338-1344.

[13] Suren D, Yildirim HT, Atalay I, Sayiner A, Yildirim M, Alikanoglu AS, et al. HMGB1 expression in urothelial carcinoma of the bladder. 2018;23(6): 1882-1886.

[14] Ahmed S, Mohammed H, Muhammad E. The Value Of Cd34 Expression In Squamous Cell Carcinoma And Urothelial Carcinoma Of The Urinary Bladder. Ain Shams Medical Journal. 2018;69(10):573-583.

[15] Hashmi AA, Hussain ZF, Irfan M, Khan EY, Faridi N, Naqvi H, et al. Prognostic significance of epidermal growth factor receptor (EGFR) over expression in urothelial carcinoma of urinary bladder. BCM Urology. 2018;18(59):1-6.

[16] Zhang B, Wu Z, Xie W, Tian D, Chen F, Qin C, Du Z, Tang G, Gao Q, Qiu X, Wu C, Tian J, Hu $\mathrm{H}$. The expression of vasohibin-1 and its prognostic significance in bladder cancer. Exp Ther Med. 2017;14(4): 3477-84

[17] Shariat SF, Sfakianos JP, Droller MJ, Karakiewicz PI, Meryn S, Bochner $\mathrm{BH}$. The effect of age and gender on bladder cancer: a critical review of the literature. BJU International. 2010;105(3):300-308. Available from: doi:10.1111/j.1464-410x.2009.09076.x.

[18] Santana SC, Souza MF, Amaral MEP. Divergent Differentiation and Variant Morphology In Invasive Urothelial Carcinomas-Association With Muscle-Invasive Disease. Surg Exp Pathol. 2020;14. Available from: https://doi.org/10.1186/s42047-020-00066-z

[19] Shah RB, Montgomery JS, Montie JE, Kunju LP. Variant (divergent) histologic differentiation in urothelial carcinoma is under-recognized in community practice: Impact of mandatory central pathology review at a large referral hospital. Urologic Oncology: Seminars and Original Investigations. 2013;31(8): 1650-1655.

[20] Kassouf W, Agarwal PK, Grossman HB. Outcome of patients with bladder cancer with $\mathrm{pN}$ disease after preoperative chemotherapy and radical cystectomy. Urology. 2009;73:147-52.

[21] Choi JW, Kim Y, Lee JH, Kim YS. CD74 expression is increased in highgrade, invasive urothelial carcinoma of the bladder. International Journal of Urology. 2012;20(2):251-255. Available from: doi:10.1111/j.14422042.2012.03128.x

[22] Messer J, Shariat SF, Brien JC, Herman MP, Ng CK, Scherr DS, et al. Urinary cytology has a poor performance for predicting invasive or highgrade upper-tract urothelial carcinoma. BJU International. 2011;108:701705. Available from: https://doi.org/10.1111/j.1464-410X.2010.09899.x

[23] Li Q, Tang J, He E, Li Y, Zhou Y, Wang B. Differentiation between highand low-grade urothelial carcinomas using contrast enhanced ultrasound. Oncotarget, 2017;8(41):70883-70889.
[24] Jimenez, Rafael EMD, Gheiler, Edward MD, Oskanian, Peter MD, et al. Grading the Invasive Component of Urothelial Carcinoma of the Bladder and Its Relationship with Progression-Free Survival. The American Journal of Surgical Pathology. 2000;24(7):980-987.

[25] Legesse T, Matoso A, Epstein JI. PAX8 Positivity in Nested Variant Of Urothelial Carcinoma: A Potential Diagnostic Pitfall. Human Pathology. 2019;9(12). Available from: doi:10.1016/j.humpath.

[26] Yoo Y, Lee J, Park HS, Cho MS, Sung SH, Park S, et al. Histologically confirmed distant metastatic urothelial carcinoma from the urinary bladder: a retrospective review of one institution's 20-year experience. Journal of Pathology and Translational Medicine. 2020:1-8. Available from: https://doi.org/10.4132/jptm.2020.10.19.

[27] Yoneda K, Kamiya N, Utsumi T, Wakai K, Oka R, Endo T, et al. Impact of Lymphovascular Invasion on Prognosis in the Patients with Bladder Cancer-Comparison of Transurethral Resection and Radical Cystectomy. MDPI Journal Diagnostics. 2021;11(244):2-10. Available from: https://doi.org/10.3390/diagnostics11020244.

[28] Mathieu R, Lucca I, Roupret M, Briganti A, Shariat SF. The prognostic role of lymphovascular invasion in urothelial carcinoma of the bladder. Nature Reviews Urology. 2016;13(8):471-479. Available from: doi:10.1038/nrurol.2016.126.

[29] Tilki D, Shariat SF, Lotan Y, Rink M, Karakiewic PI, Schoenberg MP, et al. Lymphovascular invasion is independently associated with bladder cancer recurrence and survival in patients with final stage $\mathrm{T} 1$ disease and negative lymph nodes after radical cystectomy. BJU International 2012;111:1215-1221. Available from: doi:10.1111/j.1464410X.2012.11455.X.

[30] Muppa P, Gupta S, Frank I, Boorjian SA, Karnes RJ, Thompson RH, et al. Prognostic significance of lymphatic, vascular and perineural invasion for bladder cancer patients treated by radical cystectomy. Pathology. 2017;49(3):259-266. Available from: doi:10.1016/j.pathol.2016.12.347

[31] Chen SH, Zhang BY, Zhou B, Zhu CZ, Sun LQ, Feng YJ, et al. Perineural invasion of cancer: a complex crosstalk between cells and molecules in the perineural niche. Am J Cancer Res. 2019;9(1):1-21.

[32] Jesinghaus M, Boxberg M, Konukiewitz B, Huspenina J, Schlitter AM, Steiger K, et al. A Novel Grading System Based on Tumor Budding and Cell Nest Size Is a Strong Predictor of Patient Outcome in Esophageal Squamous Cell Carcinoma. The American Journal of Surgical Pathology. 2017;41(8):1112-1120. Available from: doi:10.1097/pas.0000000000000865

[33] Lugli A, Zlobec I, Berger MD, Kirsch R, Nagtegall ID. Tumour Budding in Solid Cancers. Nature Reviews Clinical Oncology. 2020 doi:10.1038/s41571-020-0422-y.

\section{AUTHORS}

First author- dr. Rahayu Asih Putri, Resident of the Department of Anatomical Pathology, Faculty of Medicine, Universitas Sumatera Utara, Medan, Indonesia, email ID: rahayuasihputri@yahoo.co.id.

Second Author- Dr. dr. Lidya Imelda Laksmi, M.Ked (PA), Sp.PA. Department of Anatomical Pathology, Faculty of Medicine, Universitas Sumatera Utara, Medan, Indonesia.

Third author- Dr. dr. Delyuzar, M.Ked (PA), Sp.PA(K), Department of Anatomical Pathology, Faculty of Medicine, Universitas Sumatera Utara, Medan, Indonesia.

Correspondence Author- Dr. dr. Lidya Imelda Laksmi, M.Ked (PA) Sp.PA Department of Anatomical Pathology, Faculty of Medicine, Universitas Sumatera Utara, Medan, Indonesia, email ID:lidyaimelda76@gmail.com 